\title{
Modelling the Player and Avatar Attachment based on Student's Engagement and Attention in Educational Games
}

\author{
Nooralisa Mohd Tuah ${ }^{1}$, Dinna @ Nina Mohd Nizam² ${ }^{2}$ Zaidatol Haslinda A. Sani ${ }^{3}$ \\ Faculty of Computing \& Informatics \\ Universiti Malaysia Sabah, Labuan International Campus, 87008 Labuan F.T, Malaysia
}

\begin{abstract}
The Player and Avatar attachment help to motivate a student to strengthen their engagement in gameplay. The different types of avatar designs deployed in a game have an impact on students' engagements. The avatars are designed with different roles, wherein each role offers varying motivational effects on students' engagement. Several research in human and computer interaction have assessed user engagement and user attention in a computer or system application as well as in gameplay. Among the usual approaches to assess user engagement are using questionnaire and eye-tracking. Investigating the possible use of these approaches in determining the player and avatar attachment, particularly the attachment that associated with the various avatar designs and their effect on students' engagement are inconclusive and remains untapped. Essentially, studying students' engagement and attention perception while learning enriches one's comprehension about engagement in the education segment. As such, this study proposes a new model of player and avatar attachment based on the students' engagement and focus attention on the gameplay of digital educational games (DEGs). The model is developed follows a stepwise approach consisting component identification, relationship of the components, model development, and model validation. Several components were scrutinized, summarized, and developed into the model proposed in this study. A significant attachment can determine the avatar design that may influence a student's engagement in gameplay. Hence, this study offers several constructive recommendations for future avatars in game design for education purpose, which may validate the user's engagement based on his or her focus attention.
\end{abstract} games

Keywords-Avatar; engagement; attention; digital educational

\section{INTRODUCTION}

The player-avatar attachment (PLAVA) in gameplay refers to the relationship developed between a player (student) and his or her in-game virtual representation, which is the representation also known as an avatar [1, 2]. A player develops a relationship with the avatar via in-game engagement, particularly when one is having fun while learning [1] as he or she indulges in the game activities [2]. Research conducted by Kim et al. [3] shows that the degree of attachment is one of the predictors that identifies a positive relationship that brings identification between a player and the in-game character (avatar). Such positive relationship motivates players in sustaining their engagement in gameplay.

This work is funded by a research grand under Universiti Malaysia Sabah (grant no: SLB0198-2019)
Previously, several studies had researched the effects of player and avatar attachment, relationship, and user engagement in gameplay and in learning in an educational game (i.e. [4 - 8]). However, among the studies, the approach to synchronize the different types of avatar designs and their effect on student's engagement in learning was not explored extensively. Thus, it remains under research. Moreover, to extend the study of the player attachment and in-game engagement, engaging this research with an eye-tracker can contribute to visual attention perception while learning Digital Educational Games (DEGs).

As in previous research by Mohd Tuah et al. [6], Banks \& Bowman [7], and Hwang \& Mamykina [9], they had summarized a spectrum of avatar design in a game. This spectrum varies from actual human design to abstract human design. Each of the design spectrum is exploring different roles of an avatar in gameplay, such in $[5,6,8]$. As such, the following question is posed: Can students' engagement and their attention toward their avatar design and roles be modelled in defining PLAVA in the context of DEG gameplay?

Therefore, in this study, we developed a Player-Avatar attachment model by implementing avatar design types and their roles adapted to learning on DEGs. We developed the model to demonstrate how the player, which is a student, and avatar attachment can affect the way they engage based on visual attention in a game. The visual attention is modelled based on the eye-tracking metrics, which can precisely quantify the user's attention and gaze. Hence, enrich understanding of engagement in learning. We aim to investigate the Player and Avatar attachment effects on each avatar design to the avatar roles in gameplay. The significant attachment will determine which type of designs could influence the student's engagement in a game and how visual attention can validate the result. This research provides a constructive recommendation for future Avatar's game design in education and validates user's engagement based on the user's focused attention.

The remaining of this paper is structured as follows. The next section presents the background study of the avatar design, roles, the player and avatar relationship, and the user engagement evaluation. Following the literature is the method used to develop the model, in which the processes involved in model development and validation are discussed in detail. After that, this paper presents the proposed model in the result section, as well as the outcome of the model validation study. 
Moving on, the evaluation study plan is described to future endeavor. Finally, a summary of this study and the concluding remarks are presented.

\section{BACKGROUND STUDY}

An avatar denotes the representation of a player in a gameplay. Notably, an avatar is the resemblance of a player in a virtual setting [1] with its human quality and features [1, 5 6]. Avatar designs exist in varying forms of humanism, such as in iconic form, cartoonish, or a combination of designs between them. For instance, Kao and Harrel [5] found that three avatar designs; scientist avatar (i.e., Einstein), athlete avatar (i.e., Michael Jordan), and shape avatar (i.e., square, hexagon, etc.), had influenced both game performance and game experiences in educational games. The scientist avatar emerged as the most significant avatar in science, technology and mathematic educational game. This finding is consistent with the criteria of an effective role model in boosting academic performance, particularly for competent, in-group member, and success domains. Banks \& Bowman [7] outlined four categories of avatar designs (object, 'me' (oneself), symbiote, and the social other) to determine the social relationship between a player and his or her avatar in the gameplay. Upon validating the merged metric for player avatar interaction, the study identified four essential factors (emotional investment, anthropomorphic autonomy, suspension of disbelief, and sense of player control) that dictated the player-avatar interaction. Another study classified the avatar designs into several characters, including lifelike, human cartoon, medium human-like, hybrid, and abstract characters [6]. These classifications of anthropomorphic characters enable designers to develop more significant interactions for individuals in promoting a long-term relationship. Hence, this study investigated the various types of avatar designs that affected the players' engagement in gameplay.

Several studies have examined the effects among PLAVA, relationship, and user engagement in gameplay $[7-8,10]$. The player-avatar relationship signifies how a player perceives and responds to social interaction as if the player has a real social relationship with the avatar [7]. This social relationship is built while being engaged in a particular environment. Studies based on Human-Computer Interaction such as in [8, 11 - 13] perceived being engaged as the amount of time users spend doing their work (add, use or manipulate the content) or interacting with other users on the application/software/system. The social relationship between players and their avatar denotes the way players perceive themselves toward their online version (avatar) [10]. In the context of this present study, the amount of time indicates a series of temporal interaction a player spends in gameplay.

Temporal interactions exist when players spend time toward completing the assigned tasks or achieving the goal of the game. In this sense, when players are attached to their avatar, they tend to develop a social relationship and a sense of immersion in the gameplay [3]. The PLAVA is materialized when players recognize and respond to their avatar as though they are connected, similar to the social attachment established in the gameplay [7]. When playing, the player and its avatar are considered as a 'unified person'. A positive 'unified person' yields a high level of engagement. This notion emphasizes the sense of being attached to an avatar that can significantly affect the user's experience and enjoyment in the game [3 - 5].

In light of students' engagement and their avatar attachment in digital educational games (DEGs), several studies have assessed the player-avatar correlation in learning [14 - 16]. Game-based learning on DEGs makes a formal learning environment into a fun and enjoyable situation within the digital setting. According to Qian and Clark [17], use of games in classroom is integral to enhance students' motivation in learning. Similarly, Huizenga et al. [16], who studied the perception of teachers on DEGs in a classroom, revealed that DEGs increased both engagement and motivation amongst students in learning. Therefore, DEGs sustain engagement amongst students throughout the learning process, while simultaneously increasing their cognitive skills after several attempts playing the game [17]. Following All et. al. [18], this not only improves the learning effect, but also achieves the learning outcomes stipulated in each DEG. These studies disregarded the effect of each avatar design on students' engagement in learning. Therefore, more studies are called to determine avatar designs that may establish better attachment with the players, so as to make learning activities fun.

Despite the various types of avatar designs in educational games, avatars typically represent a student's selfrepresentation [14] or as a tutor or a virtual teacher [19]. The use of avatar should not be restricted to the representation of a user, but should cover specific roles to encourage social interaction, including as a customization tool [20], as an ingame strategy [9], or as a personal identification [6, 8, 15]. As a customization tool, users may freely customize their avatars based on the purpose and the rules of the game [1]. For instance, players can change the appearance of their avatar (e.g., shirt, shoes, hair, eyes, nose, etc.), or add accessories to the avatar (e.g., bag, umbrella, skateboard, etc.). Meanwhile, for an avatar as an in-game strategy, the avatar appearance can be part of the game strategy to gain a winning point or to achieve the goal of the game [9]. The best avatar may be selected by the player to deal with the challenges in the game. Avatar with a stronger character (bold, fierce, and muscular) is usually chosen in strategizing the gameplay. Framing the player's real-life situations can also be part of gaming strategies for personal improvement and motivation [21]. In personal identification, the players may integrate their personalities with the avatar [16, 22], but limited to the options available in the game.

Further exploration into the type of avatar design yields its significant impact on a player's engagement, which reflects a reliable 'unified person' deployed in DEGs. A 'unified person' indicates the attachment between a player and its avatar, which is significantly connected to the DEG gameplay. Past studies had assessed engagement among players through their avatar in gameplay using questionnaires [7 - 8]. The questionnaire has been applied to collect individual perceptions on the use of games for particular purposes. This method captures important information concerning engagement and can further support one's perception toward his or her engagement in a gameplay. Another viable measurement tool is eye-tracking. In this 
method, the players' engagement with their avatar and environment is measured through visual attention perception, thus making this tool particularly useful for DEGs. In this case, it is for the purpose of learning using DEGs.

The eye-tracking method gathers a user's behaviour by tracking the eye movement in a natural interaction setting [23]. Several studies had applied the eye-tracking technology to examine the effects of graphics [24], reading [22], and recently, DEGs in young children [25]. Several indicators, including fixation duration, total number of fixations, and time-to-firstfixation, are grounded measures of attention paid to objects of interest [26]. Visual attention or focused attention refers to the attention span during interaction and how one loses track of time when interacting in a given environment [11]. One gets absorbed when one has full concentration on mental activities while ignoring the rest [11]. By deploying this eye-tracking method, visual attention is measured using fixation-based metrics, as detailed in [27]. The metrics refer to the attention that spans in a certain duration associated with intensive facial expression and eye movements [22]. Analyzing the fixation duration on a defined Area of Interest (AOI) in DEG environment determines if an avatar design has an impact on the relationship with and on the behavior of a student's gameplay engagement. The longer a player focuses on the defined AOI from the fixation duration, the more information can be captured if the fixation duration is linked with the player's engagement behavior. In studying the effect of PLAVA on a user's engagement, it is essential to investigate the correlation between the type of avatar design and its related roles in the game.

This paper proposes a player-avatar attachment (PLAVA) model. The model is developed to assess the impact of PLAVA on the player's interaction with varying avatar designs and their designated roles in gameplay. Following the player's interaction, a significant attachment can determine the type of avatar designs that may influence his or her engagement in a game. The model is composed of two aspects, as mentioned earlier, namely avatar design types and avatar roles in learning using DEGs. In the model, the relationship between player and avatar is perceived through the components of engagement and attention. The component of engagement is modelled to understand the player's perception toward his or her connection with the avatar. The model incorporates the engagement component derived from questionnaires developed by [7] and [11]. Meanwhile, the attention component is retrieved from visual attention attributes and eye-tracking metrics, in order to precisely quantify the attention and gaze of the users. Hence, the student's perceptions toward engagement are supported by their visual attention data captured using the eye-tracking method. The data input can enrich the understanding of engagement in learning. Lastly, this study provides several constructive recommendations for future avatars in game design for education purpose, besides validating the users' engagement based their focused attention. This study significantly contributes to the body knowledge pertaining to creative content in DEGs and eye-tracking technology.

\section{Methodology}

In the model development, a step-by-step approach was followed to ensure the applicability of the model whether in research or in practice. However, when developing the model, it is deemed necessary to confirm the significance of each components identified in the model. The model development processes will be explained in detail followed by the explanation of expert review studies in validating the proposed model.

\section{A. The Model Development Process}

A stepwise approach was adopted to develop the proposed model. In the initial step, the development process began with component identification. In this process, variables related to the PLAVA, as well as students' engagement and attention, were identified, analyzed, and refined by reviewing articles published since a decade ago (2010-2020). Articles published in the area of human-computer interaction and educational games were incorporated. There on, details of the sought components were scrutinized after considering the importance and the relevance of each article. After identifying all the components, each component and sub-component had been defined. Defining both the scope and the purpose of each component can be plausibly helpful in model creation.

In the second step, input and output variables for each component were listed. By doing so, potential relationships or connections among the variables were further explored to develop the model. In particular, this step determined the flow and link between input and output of the components. As for the third step, the selected components and the inter-connection among the components were embedded to build the conceptual model for this study. In the final step, a validation study was conducted to validate the idea and concept of the model. Fig. 1 illustrates the model development process.

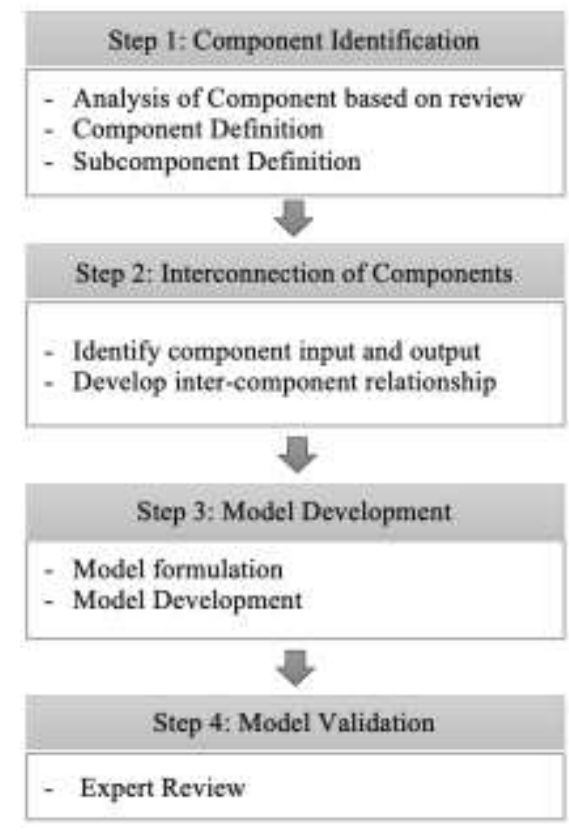

Fig. 1. The PLAVA Model Development Process. 


\section{B. Component Identification}

Prior studies have excluded the engagement component in PLAVA in light of avatar roles. Most of the past studies had looked into agency as a tool to measure engagement $[3,5]$. In view of this, the agency has been linked with the user's sense of agency with autonomy toward body ownership. Several considerations must be weighed in to measure the level of engagement based on PLAVA, including the method and the motivation of measurement. For instance, Hookham [13] had identified many strategies deployed to measure engagement in a series of game field and categorized them into interviews, focus groups, questionnaires, as well as direct and indirect observations. Meanwhile, Doherty et al. [12] classified the methods in a more structured and explicit manner. They categorized the methods of measuring engagement into two; subjectivity- oriented and objectivity-oriented. Subjectivityoriented refers to perception and usually adopts the questionnaire as a tool, such as the User Engagement Scale (UES) [11] and the Game Engagement Questionnaire (GEQ) [28]. The UES is a tool that evaluates engagement in a setting of information search, system application or video games environment. Meanwhile, GEQ is used to specifically measure the impact of engagement on playing video games. As for objectivity-oriented, it is a measurement of engagement without directly questioning the users. For example, the electroencephalography (EEG) is applied to trace the behavior displayed by users in exerting action/transaction, as well as the eye-tracking method [25]. The methods were adopted based on the study purpose; either to comprehend the fundamentals of engagement, to design engagement and practice it, or to implement the components of engagement in system development [12].

Focused attention is one of the attributes used to measure the level of user engagement in gameplay. It refers to the feel of being absorbed in the game during interaction and how they lose track of time when interacting [11]. The feeling of being absorbed happens when users completely concentrate on mental activities while ignoring the rest [11]. In most engagement measurement tools, such as GEQ [28] and UES [11], focused attention is measured in accordance with the users' perceptions of their concentration and loss of time in their gaming experiences. The tools weigh in users' subjectivity measures. These perceptions, nonetheless, may be further comprehended when they are quantified using other methods, such as the eye-tracking method.

On the other hand, attachment had been assessed in past studies based on the effect of players' game experiences, interaction, and enjoyment. A study using the PLAVA model by [7] contended that there are other significant elements in the model, namely sociality and character attachment. Sociality includes emotional investment, anthropomorphic autonomy, suspension of disbelief, and sense of control. Banks \& Bowman assessed all these components to measure the extent of players' sense of themselves in gameplay in terms of agency, presence, and engagement. These components are applicable to DEGs as well. The attachment that a player has to an avatar can significantly affect physical presence, emotional presence, and narrative presence, particularly when the environment involves avatar customization [3]. As reported in [3], the attachment established between a player and an avatar can significantly affect enjoyment as well.

A study by Mohd Tuah [29] modelled the motivational design of avatar based on its role in gameplay. The roles are inclusive of a player's profile identification or in-game character. For profile identification, players may set their profile by selecting the available avatar as their affiliation and also as their in-game character. The players are allowed to choose their preferred avatars to represent themselves in the gameplay. The relationship established between the player and the avatar is based on the avatar roles in the game. Nevertheless, the model excluded other method(s) to validate the relationship. Apparently, the application of avatar, at some point, will effectively motivate the users, thus engage the players. However, this engagement varies depending on the condition and the environment where the avatar is applied - if the avatar is designed in 3D/2D model or if it is merely a flat image or if it is animated with the variation of avatar design types. Table I lists the variation of avatar design types reported in past studies. The interpretation of avatar types are as follows: 1) human character (lifelike or cartoonish), 2) hybrid (unrealistic human mix between human and animal design), and 3) abstract human form design.

On another note, DEG is also a part of serious games; whereby in a healthcare environment, DEG is used mainly to assist patients in learning and comprehending their condition, as well as for health self-management. For example, Hwang and Mamykina [9] applied DEGs to encourage a healthier lifestyle. They used an avatar as the player's representation that changed based on the choices of high- or low-calorie snacks intake. The players (patients) eventually learnt about nutrition intake and its impact on their body. Their study revealed that DEGs could significantly affect the healthcare environment on a larger scale.

TABLE I. SUMMARY OF AVATAR DESIGN TYPES

\begin{tabular}{|c|c|c|c|c|c|c|}
\hline \multirow{2}{*}{$\begin{array}{l}\text { Article } \\
{[31]}\end{array}$} & \multicolumn{5}{|c|}{$\begin{array}{l}\text { Human lifelike } \\
\text { character }\end{array}$} & \multirow{2}{*}{$\begin{array}{l}\begin{array}{l}\text { Abstract Human } \\
\text { Form Design }\end{array} \\
\text { Low } \\
\text { (anthropomorphism) } \\
\text { (4) }\end{array}$} \\
\hline & $\begin{array}{l}\text { Real } \\
\text { Human } \\
\text { Image } \\
\text { (1) }\end{array}$ & $\begin{array}{l}\text { High } \\
\text { (anthrop } \\
\text { phism) } \\
\text { (2) }\end{array}$ & & $\begin{array}{l}\text { Medium } \\
\text { (anthrop } \\
\text { phism) } \\
\text { (3) }\end{array}$ & nor & \\
\hline [5] & \multicolumn{2}{|c|}{$\begin{array}{l}\text { the scientist avatar } \\
\text { (1) }\end{array}$} & \multicolumn{3}{|c|}{$\begin{array}{l}\text { athlete avatar } \\
\text { (2) }\end{array}$} & $\begin{array}{l}\text { shape avatar } \\
\text { (3) }\end{array}$ \\
\hline [7] & \multicolumn{2}{|c|}{$\begin{array}{l}\text { Me (oneself) } \\
\text { (1) }\end{array}$} & $\begin{array}{l}\text { Symbiote } \\
(2)\end{array}$ & \multicolumn{2}{|l|}{$\begin{array}{l}\text { Object } \\
(3)\end{array}$} & $\begin{array}{l}\text { social other } \\
(4)\end{array}$ \\
\hline [6] & $\begin{array}{l}\text { Human } \\
\text { lifelike } \\
\text { character } \\
(1)\end{array}$ & $\begin{array}{l}\text { human } \\
\text { cartoon } \\
\text { character } \\
(2)\end{array}$ & \multicolumn{2}{|c|}{$\begin{array}{l}\text { medium } \\
\text { human-like } \\
\text { character } \\
\text { (3) }\end{array}$} & $\begin{array}{l}\text { hybrid } \\
\text { charac } \\
\text { (4) }\end{array}$ & $\begin{array}{l}\text { abstract } \\
\text { character } \\
(5)\end{array}$ \\
\hline [4] & \multicolumn{2}{|c|}{$\begin{array}{l}\text { Human (high } \\
\text { anthropomorphism) } \\
\text { (1) }\end{array}$} & \multicolumn{3}{|c|}{$\begin{array}{l}\text { Robot (high } \\
\text { anthropomorphism) } \\
\text { (2) }\end{array}$} & $\begin{array}{l}\text { Block-like (low } \\
\text { anthropomorphism } \\
\text { (3) }\end{array}$ \\
\hline [30] & $\begin{array}{l}\text { Realistic } \\
\text { humans } \\
\text { (1) }\end{array}$ & $\begin{array}{l}\text { Humar } \\
\text { machir } \\
\text { (2) }\end{array}$ & & $\begin{array}{l}\text { Unrealis } \\
\text { human } \\
\text { (3) }\end{array}$ & & $\begin{array}{l}\text { Abstract human } \\
\text { form } \\
\text { (4) }\end{array}$ \\
\hline [19] & $\begin{array}{l}\text { Kinect- } \\
\text { Video } \\
\text { (Human) } \\
\text { (1) }\end{array}$ & $\begin{array}{l}\text { Humal } \\
\text { Model } \\
\text { (2) }\end{array}$ & & $\begin{array}{l}\text { Robot-M } \\
\text { (human- } \\
\text { robot) } \\
(3)\end{array}$ & & $\begin{array}{l}\text { Hybrid (Real } \\
\text { Human + Robot) } \\
\text { (4) }\end{array}$ \\
\hline
\end{tabular}


Hence, investigating the aspect of engagement based on avatar types and roles using the platform of DEGs can shed light on the personal avatar effects, as well as the best way to deliver them. In DEGs, it is integral to identify the learning outcome of the game, which serves as a measurable indicator in determining the player's achievement.

Following the above discussion, several components were identified as the factors in modelling the PLAVA in light of students' engagement and attention in DEGs. The components include avatar designs and roles in DEGs; player's demographic, learning outcome, and engagement - attention; aesthetics appeal; perceived usability; reward; character attachment; and sociality.

\section{Definition of Components}

Based on the processes exemplified above, the definition of each component is as follows:

- The avatar design - It denotes the avatar and its roles. Notably, the avatar and its roles can affect the way a player engages in the DEG environment. This component specifies the selection of avatar type and its implementation in the games, as described previously for avatar design roles.

- The learning outcome - each educational game has its learning outcome to be achieved at the end of the game. Learning outcomes provide further insight into the relationships among the engagement components (attention, character, aesthetic usability, and rewards), particularly on the significance of the attributes in achieving the learning outcome of the games.

- The engagement - This component is about measuring the engagement of the players in DEGs. Several measurements can be considered, including 1) character attachment and sociality adopted from Banks \& Bowman [7], 2) game engagement scale by O'Brien et al. [11], and 3) focus attention using the eye-tracking method to extract fixation-based data.

\section{Interconnection among the Components}

The PLAVA is interrelated between the setting fixed for the DEG environment and the components that determine the players' engagement in the DEG. The DEG environment takes into account three sub-components, namely player's demographic profile, learning outcome, and avatar design. These three components are interrelated to strongly justify the DGE environment. The determined learning outcome can influence the selection of avatar type and design. One with vital gaming skill and knowledge in the context of games environment can positively affect the PLAVA or vice versa.

In determining the engagement among students, several measurement factors are inter-related to each other. As defined earlier, the engagement components include measuring avatar attachment with sociality, game engagement, and focus attention. For avatar and game, the measurement tool is surveybased tools to measure PLAVA and the player's engagement with DEGs. To further support the survey data, fixation-based data were incorporated to assess engagement. By using the fixation-based data, which were gathered from the eye-tracking method, the players' focus attention was calculated and compared with the survey data.

\section{E. Model Development and Validation}

Following the component identification and their intercomponent relationships, the conceptual model was developed, as presented in the result section. In the development stage, the focus was on refining the flow of the components, particularly on how the components interacted with each other. Several attempts to formulate the model were made via idea brainstorming and discussions. The final developed model was then agreed upon after considering all issues discussed in this paper. As we discussed earlier, the developed model requires validation. Next, this paper explains the validation studies conducted in this study.

1) Validation study with expert review: Insights from research experts will be beneficial in validating the model. Conducting an expert review will helps to uncover the model limitations, uncertainties and problems that might not detected from the literature [32]. Thus, an expert review is planned and conducted to validate the model. For that, this study employed a focus group discussion. The focus group discussion is mainly to get further feedback on the developed model and the developed games as well as to put in place the future work related to the model. We asked these experts to identify any components that ambiguous and related comments for adjustments to improve the model. From this expert review studies, it helped the authors to answer some questions and rectified the misconceptions during the model development stage.

2) Participant and design: We conducted a focus group discussion to the experts in the field. The review studies were participated with five experts. A minimum of five experts are plausible to find average proportion of problems in heuristics evaluation [33]. The five experts are identified based on their expertise in the field of human-computer interaction, especially in user experiences, educational games, and aesthetics. All identified experts agreed to participated.

The review session is designed to be conducted via online meeting. The experts are invited to participate in the study via email. Once they agreed, details and materials of the meeting are sent to them for further action. Their consent to the studies is collected via email prior to the meeting. During the session, procedures of the discussion especially related to question-andanswer session were briefed beforehand. After the briefing, introduction to the model is presented followed by the discussion. The online meeting lasts two hours.

\section{RESUlT AND DisCUSSION}

\section{A. The Player and Avatar Attachment Model}

After analyzing the related components and synthetizing the relationships among the components for PLAVA in DEGs, the conceptual model for this study was built. Fig. 2 illustrates the proposed conceptual model for this study. 


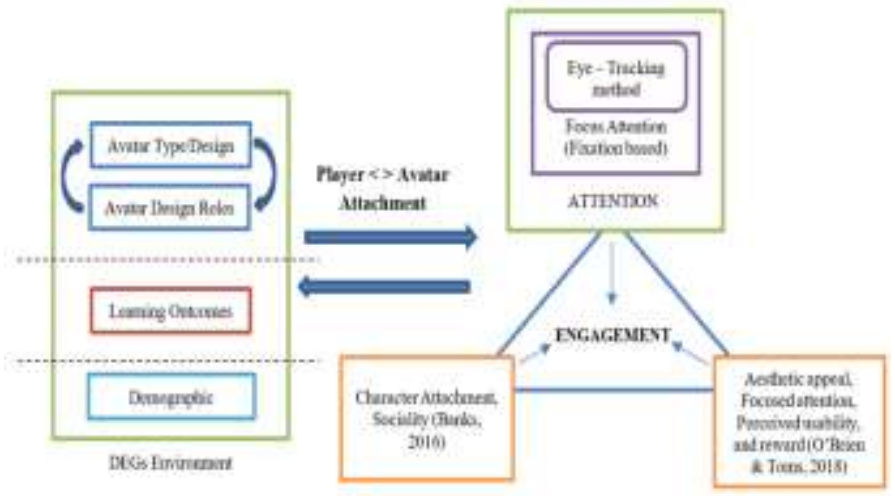

Fig. 2. The Player-Avatar Attachment Model.

In the PLAVA model, the DEGs environment involved with avatar type, avatar design roles, DEGs learning outcomes, and student's demographic. For engagement, it involved with attention, character attachment and sociality, and game engagement. From the PLAVA model, the main hypothesis is the avatar type (humanoid (x)) applied as (avatar design roles (y)) has positively affected the way a player engages in DEGs. Whereby $\mathrm{x}$ is a human character, hybrid design, and abstract design. Variable y is the identification and in-game character.

Meanwhile, as of the engagement, the PLAVA model has incorporated the elements to measure the player's engagement effect of the avatar in DEGs. Following the proposed model, it is assumed that the selected indicators have an integral role in defining the PLAVA within the context of DEG gameplay. Hence, the validation study in this area could address each component embedded in the PLAVA Model, so as to determine the effect of all the model components on the players in DEGs gameplay.

\section{B. Result of the Expert Reviews}

Five experts participated in the review studies. The demographic of the experts is summarized in Table II. The distribution of experts is appropriate considering their years of experiences, field of expertise, and the employment status. Three main questions were asked during the session.

1) What do you think about the model?

2) Do you find any ambiguous components in the model?

3) Do you have any comments to improve the model?

We analyzed the findings for the first question and summarized them in Table III. For the first question, findings in Table III show that all experts had agreed that the element of engagement and attention were the main factors in defining player attachments towards their avatar and the games. These factors were consistent with the reviews of engagement and attention in the component identification section in this paper. Two experts find that demographic component does not totally matters in the model. However, the other three experts contended the demographic is needed to analyze the player's perspective based on their background. Thus, the demographic component remains in the model. Therefore, based on the analysis of first question, the experts mutually have accepted the proposed model.
TABLE II. EXPERT DEMOGRAPHIC

\begin{tabular}{|l|l|}
\hline Demographic & No \\
\hline Gender & 3 \\
\hline Female & 2 \\
\hline Male & \multicolumn{2}{l|}{} \\
\hline Age & 3 \\
\hline $35-40$ & 2 \\
\hline $40-45$ & \multicolumn{2}{l|}{} \\
\hline Employment Status & 3 \\
\hline Senior Lecturer & 1 \\
\hline Researcher & 1 \\
\hline Post-Doctorate & \multicolumn{2}{l|}{} \\
\hline Field of Expertise & 2 \\
\hline User experiences & 2 \\
\hline Educational games & 1 \\
\hline Aesthetics & 1 \\
\hline Years of experiences in the field & 3 \\
\hline $3-5$ & 1 \\
\hline 6 - 9 & \multicolumn{2}{|l|}{} \\
\hline 10 and Above & 1 \\
\hline
\end{tabular}

For the second question, there were a consistent remark from the experts on two issues that need further clarification. The issues are: 1) if the model should adopt all the items or adapt only some items accordingly, and 2) which type of avatar designs should be used to assess PLAVA and which avatar should be planned comprehensively. For the first issue, the PLAVA model incorporated all measurement items derived from Banks \& Bowman [7] and O'Brien et al. [11]. In total, 30 (five items for each factor) items were used in the PLAVA model. As for the avatar type of design, five avatar designs were implemented (real human character, human cartoonish, a mix design between human and animal design, hybrid design (between animal and abstract design), and abstract design). These avatar designs were retrieved from [6].

TABLE III. EXPERT PERSPECTIVE ABOUT THE PROPOSED MODEL

\begin{tabular}{|c|c|c|c|c|c|}
\hline \multirow{2}{*}{ Component } & \multicolumn{5}{|c|}{ Experts Agreement } \\
\hline & $E 1$ & $E 2$ & $E 3$ & E4 & E5 \\
\hline \multicolumn{6}{|l|}{ DEGs Environment } \\
\hline Avatar Type / Design & $\sqrt{ }$ & $\sqrt{ }$ & $\sqrt{ }$ & $\sqrt{ }$ & $\sqrt{ }$ \\
\hline Avatar Design Roles & $\sqrt{ }$ & $\sqrt{ }$ & $\sqrt{ }$ & $\sqrt{ }$ & $\sqrt{ }$ \\
\hline Learning Outcomes & $\sqrt{ }$ & $\sqrt{ }$ & $\sqrt{ }$ & $\sqrt{ }$ & $\sqrt{ }$ \\
\hline Demographic & $\mathrm{x}$ & $\mathrm{x}$ & $\sqrt{ }$ & $\sqrt{ }$ & $\sqrt{ }$ \\
\hline \multicolumn{6}{|l|}{ Engagement } \\
\hline $\begin{array}{l}\text { Character Attachment } \\
\text { Sociality }\end{array}$ & $\sqrt{ }$ & $\sqrt{ }$ & $\sqrt{ }$ & $\sqrt{ }$ & $\sqrt{ }$ \\
\hline Attention (focus attention) & $\sqrt{ }$ & $\sqrt{ }$ & $\sqrt{ }$ & $\sqrt{ }$ & $\sqrt{ }$ \\
\hline $\begin{array}{l}\text { Aesthetic appeal, focus } \\
\text { attention, perceived usability, } \\
\text { rewards }\end{array}$ & $\sqrt{ }$ & $\sqrt{ }$ & $\sqrt{ }$ & $\sqrt{ }$ & $\sqrt{ }$ \\
\hline
\end{tabular}


As of the third question, the comments were mainly discussing about the evaluation study. Two important points were highlighted in planning and conducting the evaluation study. One is associated with the completeness of the games, while the second is about the eye-tracking experimental setup. Game completeness is important to avoid bias. Bias may result from a player's confused state, mainly because instead of responding about the engagement, the player's responses could be influenced by the game usability. The second point is linked with the eye-tracking method. A step-by-step procedure should be outlined prior to the experiment.

As a result, the plan for the evaluation study is as follows: Two different games were installed to imply each one of the two different avatar roles (customization and personal identification). Each game deployed all the avatar types in the gameplay. Thus, with the two conditions (roles) and five variables (avatar types), ten sets of games were prepared to perform the evaluation study. The students were required to play each game for 20-30 minutes. In the end, they would have to reach a specific goal as the point of achieving the learning outcome(s) of the game.

\section{CONCLuSION}

Using Player-Avatar attachment as a method to define which avatar design and what roles that can be used to develop a sustainable engagement and attention in the DEG's gameplay require a careful attention. In general, having a well-presented avatar can help to boost a player's motivation to engage in the gameplay. However, the type of avatar design that can offer optimum attachment in DEG gameplay remains untapped. In order to understand the student's engagement in learning, methods other than the self-reflecting/preferences questionnaire tool should be employed. Essentially, the mixed method is bound to enrich the findings. One may further explore the player's visual attention by using the eye-tracking method. Upon combining these varying methods, there is high potential to develop an all-comprehensive PLAVA for future DEG design. Hence, this paper proposes a model for players (student) and their in-game avatar attachment in the context of DEG gameplay. The attachment could improve students' engagement in many different ways. By determining the avatar design type that can influence the PLAVA in DEG gameplay, suitable avatar designs may be applied for educational games in the future. For future work, an evaluation experiment will be performed to assess the PLAVA using the game that was created for this purpose. The design of the evaluation experiment will be derived from the validation study performed in this paper. Overall, ample opportunities are present for an avatar to serve as a significant social model for effective learning via game.

\section{ACKNOWLEDGMENT}

Authors would like to thank the university for the support and opportunities given in conducting the research as well as the participants who participate in completing this study.

\section{REFERENCES}

[1] Turkay, S., \& Kinzer, C. K., "The Effects of Avatar-Based Customisation on Player Identification", International Journal of Gaming and Computer-Mediated Simulations, vol. (6), no. (1), pp. 1-25, 2014.
[2] Wang, W., Zhao, Y., "Attributions of human-avatar relationship closeness in a virtual community", Lecture Notes in Computer Science (including subseries Lecture Notes in Artificial Intelligence and Lecture Notes in Bioinformatics), vol. (5288 LNAI), pp. 61-69, 2008.

[3] Kim, K., Schmierbach, M. G., Bellur, S., Chung, M. Y., Fraustino, J. D., Dardis, F., \& Ahern, L., "Is it a sense of autonomy, control, or attachment? Exploring the effects of in-game customisation on game enjoyment", Computers in Human Behavior, vol. (48), pp. 695-705, 2015.

[4] Kao, D., \& Harrell, D. F. "Toward avatar models to enhance performance and engagement in educational games", In Proceeding of the IEEE Conference on Computational Intelligence and Games, pp. 246-253, 2015.

[5] Kao, D., \& Harrell, D. F., "Exploring the impact of role model avatars on game experience in educational games", In Proceedings of the 2015 Annual Symposium on Computer-Human Interaction in Play, pp. 571576, 2015.

[6] Mohd Tuah, N., Wills, G., \& Ranchhod, A., "The Characteristics and Application of Anthropomorphic Interface: A Design Spectrum", In Proceeding of The Ninth International Conference on Advances in Computer-Human Interactions, Venice, 24-28 Apr 2016, ThinkMinds, pp. 398-402, 2016.

[7] Banks, J., \& Bowman, N. D., "Emotion, anthropomorphism, realism, control: Validation of a merged metric for a player-avatar interaction (PAX)", Computers in Human Behavior, vol. (54), pp. 215-223, 2016.

[8] Wiebe, E. N., Lamb, A., Hardy, M., \& Sharek, D., "Measuring engagement in video game-based environments: Investigation of the User Engagement Scale", Computers in Human Behavior, vol. (32), pp. 123-132, 2014.

[9] Hwang, M., \& Mamykina, L., "Monster Appetite: Effects of Subversive Framing on Nutritional Choices in a Digital Game Environment", In Proceedings of the 2017 CHI Conference on Human Factors in Computing Systems, ACM, Denver, CO, USA, pp. 4082-4096, 2017.

[10] Sibilla, F., \& Mancini, T, "I am (not) my avatar: A review of the useravatar relationships in Massively Multiplayer Online Worlds", Cyberpsychology: Journal of Psychosocial Research on Cyberspace, vol. (12), no. (3), article 4, 2018.

[11] O'Brien, H. L., Cairns, P., \& Hall, M., "A practical approach to measuring user engagement with the refined user engagement scale (UES) and new UES short form", International Journal of HumanComputer Studies, vol. (112), pp. 28-39, 2018.

[12] Doherty, K., \& Doherty, G., "Engagement in HCI: Conception, theory and measurement", ACM Computing Surveys, vol. (51), no. (5). 2019.

[13] Hookham, G., \& Nesbitt, K., "A Systematic Review of the Definition and Measurement of Engagement in Serious Games", In Proceedings of the Australasian Computer Science Week Multiconference (ACSW 2019), ACM, New York, USA, Article 42, pp. 1-10, 2019.

[14] Barata, G., Gama, S., Fonseca, M. J., Gonçalves, D., \& Jorge, J., "Improving student creativity with gamification and virtual worlds", In Proceedings of the First International Conference on Gameful Design, Research, and Applications - Gamification '13, New York, NY, USA: ACM, pp. 95-98, 2013.

[15] Birk, M. V., Atkins, C., Bowey, J. T., \& Mandryk, R. L., "Fostering Intrinsic Motivation through Avatar Identification in Digital Games", Proceedings of the 2016 CHI Conference on Human Factors in Computing Systems - CHI '16, pp. 2982-2995, 2016.

[16] Huizenga, J. C., ten Dam, G. T. M., Voogt, J. M., \& Admiraal, W. F., "Teacher perceptions of the value of game-based learning in secondary education", Computers and Education, vol. (110), pp. 105-115, 2017.

[17] Qian, M., \& Clark, K. R., "Game-based Learning and 21st century skills: A review of recent research", Computers in Human Behavior, vol. (63), pp. 50-58, 2016.

[18] All, A., Nuñez Castellar, E. P., \& Van Looy, J., "Assessing the effectiveness of digital game-based learning: Best practices", Computers and Education, vol. (92), no. (93), pp. 90-103, 2016.

[19] Woodworth, J. W., Lipari, N. G., \& Borst, C. W., "Evaluating teacher avatar appearances in educational VR", In Proceeding of 26th IEEE Conference on Virtual Reality and 3D User Interfaces, pp. 1235-1236. 2019. 
[20] Lin, L., Parmar, D., Babu, Sf. V., Leonard, A. E., Daily, S. B., \& Jörg, S., "How character customisation affects learning in computational thinking", In Proceedings of the ACM Symposium on Applied Perception - SAP '17, pp. 1-8, 2017.

[21] Tuah, N.M., Yoag, A., Ahmedy, F., \& Baharum, A., "A Gamification and Avatar Self-representation application for Diabetes SelfManagement", International Journal of Advanced Trends Computer Science Engineering, vol. (8), no. (1.6), pp. 401-407, 2019.

[22] Hector R Ponce and Richard E Mayer., "An eye movement analysis of highlighting and graphic organiser study aids for learning from expository text", Computers in Human Behavior, Vol. (41), pp. 21-32, 2014.

[23] Moayad Mokatren, Tsvi Kuflik, Ilan Shimshoni, "Exploring the potential of a mobile eye tracker as an intuitive indoor pointing device: A case study in cultural heritage", Future Generation Computer Systems, vol. (81), pp. 528-541, 2018.

[24] Marta Koć-Januchta, Tim Höffler, Gun-Brit Thoma, Helmut Prechtl, Detlev Leutner, "Visualizers versus verbalizers: Effects of cognitive style on learning with texts and pictures - An eye-tracking study", Computers in Human Behavior, vol. (68), pp. 170-179, 2017.

[25] Mohd Nizam, Dinna \& Law, Lai-Chong., "In the Eyes of Young Children: A Study on Focused Attention to Digital Educational Games", In Proceedings of the 32nd International BCS Human-Computer Interaction Conference (HCI), Belfast, 4 - 6 July 2018.

[26] Steichen, B., Wu, M. M. A., Toker, D., Conati, C., \& Carenini, G., "Te,Te,Hi,Hi: Eye Gaze Sequence Analysis for Informing UserAdaptive Information Visualisations", In V. Dimitrova, T. Kuflik, D. Chin, F. Ricci, P. Dolog, \& G.-J. Houben (Eds.), User Modeling,
Adaptation, and Personalisation. UMAP 2014, Lecture Notes in Computer Science, vol. (8538), pp. 183-194, 2014.

[27] Borys, M., \& Plechawska-Wójcik, M., "Eye-tracking metrics in perception and visual attention research", European Journal of Medical Technologies, vol. (3), pp. 11-23. 2017.

[28] Brockmyer, J. H., Fox, C. M., Curtiss, K. A., McBroom, E., Burkhart, K. M., \& Pidruzny, J. N., "The development of the Game Engagement Questionnaire: A measure of engagement in video game-playing", Journal of Experimental Social Psychology, vol. (45), no. (4), pp. 624634, 2009.

[29] MohdTuah, N., Wanick, V., Ranchhod, A., \& B Wills, G., "Exploring avatar roles for motivational effects in gameful environments", EAI Endorsed Transactions on Creative Technologies, vol. (4), no. (10). 2017.

[30] Lugrin, J.-L., Latt, J., \& Latoschik, M. E., "Anthropomorphism and Illusion of Virtual Body Ownership", In Proceedings of the 25th International Conference on Artificial Reality and Telexistence and 20th Eurographics Symposium on Virtual Environments, pp. 1-8, 2015.

[31] Gong, L., "How social is social responses to computers? The function of the degree of anthropomorphism in computer representations", Computers in Human Behavior, vol. (24), no. (4), pp. 1494-1509. 2008.

[32] Sweetser, P., Johnson, D., Wyeth, P., Anwar, A., Meng, Y., \& Ozdowska, A., "Game Flow in Different Game Genres and Platforms", Computer Entertainment, vol. (15), no. (3), article 1, pp. 1-24, 2017.

[33] Nielsen, J., "Estimating the number of subjects needed for a thinking aloud test", International Journal of Human-Computer Studies, vol. (41), no. (3), pp. 385-397. 1994. http://doi.org/10.1006/ijhc.1994.1065. 